\title{
PENGELOLAAN LIMBAH MEDIS PADAT DI RSUD DR. R. SOSODORO DJATIKOESOEMO BOJONEGORO
}

\author{
Putri Nursuma Dewi, Darjati, Demes Nurmayanti
}

\begin{abstract}
RSUD R. Sosodoro Djatikoesoemo Bojonegoro is a grade B government hospital operating a number of health facilities and beds, therefore it generates large amount of solid medical wastes. A preliminary survey found that there were some issues, such as that officers did not wear full PPE, plastic bags for medical waste that is not in accordance with the guidelines were being used, and combustion residue from the incinerator were directly dumped into a landfill. The study aimed to describe the management of solid medical wastes in RSUD R. Sosodoro Djatikoesoemo Bojonegoro.

This is a descriptive type of study, involving several variables to be researched including the generation, sources and types, amount (weight), temporary storage facility, collection methods, "transportation, destruction, factors that affect amount of waste generated and factors that support the management of solid medical waste. Primary data were obtained from through observations, interviews, measurement of the amount (weight) of solid medical waste; as well as relevant secondary data. Presentation of data are mostly in the form of tabulation and analyzed descriptively with $80 \%$ compliance standard.

The result showed that solid medical wastes originated from health care activities (infectious wastes, sharps, pathological matters, radioactive, and pharmaceutical wastes). The largest amount turned out to be medical and infectious wastes ( $\pm 139.04 \mathrm{kgs} / \mathrm{day})$ and the smallest amount of waste was pharmaceutical wastes $(0.07$ $\mathrm{kgs} /$ day); these are influenced by the number vicitors, the number of patients and number of services seeked and provided. Medical waste management made a score of $73.9 \%$ (below standard) and smallest percentages were found in the organizational factors, manpower, equipments and record keeping, costs and budgets, regulations and legal foundation.

The study concluded that RSUD R. Sosodoro Djatikoesoemo Bojonegoro is below standard (73.9\%). The Hospital was adviced to treat combustion ashes before disposal to landfill, conduct monitoring of toxic chemicals, to sort medical solid wastes according to its type, replacing waste bins according to the requirements, use proper color plastic bags in accordance with the guidelines.
\end{abstract}

Keywords : management, solid waste, medical, onset, incinerator residu, plastic bags, colour system.

\section{PENDAHULUAN}

Istilah limbah/sampah sudah tidak asing lagi di telinga. Sampah telah menjadi permasalahan nasional sehingga pengelolaannya perlu dilakukan secara komprehensif dan terpadu agar memberikan manfaat secara ekonomi, sehat bagi masyarakat, dan aman bagi lingkungan, serta dapat mengubah perilaku masyarakat (UU RI No. 18 Tahun 2008).

Rumah sakit adalah institusi pelayanan kesehatan yang menyelenggarakan pelayanan kesehatan perorangan secara paripurna yang meyediakan pelayanan rawat inap, rawat jalan, dan rawat gawat darurat (UU RI No. 44 Tahun 2009). Dari kegiatan tersebut berpengaruh terhadap produksi limbah padat yang dihasilkan, baik limbah medis padat maupun non medis padat. Limbah tersebut dapat menimbulkan penyakit serta pencemaran lingkungan sehingga perlu perhatian khusus.

Pengelolaan limbah medis merupakan bagian dari kegiatan penyehatan lingkungan di rumah sakit yang bertujuan untuk melindungi masyarakat dari bahaya pencemaran lingkungan yang bersumber dari limbah rumah sakit (Asmadi, 2013). Oleh karena itu diperlukan adanya pengelolaan limbah medis padat rumah sakit.

Rumah sakit RSUD Dr. R. Sosodoro Djatikoesoemo Bojonegoro merupakan rumah sakit milik pemerintah daerah kelas B Non Pendidikan sejak tahun 2006 yang memiliki 16 fasilitas pelayanan kesehatan dan jumlah tempat tidur sebanyak 293 tempat tidur. Berdasarkan hasil survey pendahuluan yang dilakukan di RSUD Dr. R. Sosodoro Djatikoesoemo Bojonegoro pada bulan Januari 2014 ditemukan beberapa masalah yaitu masih terdapat petugas pengelola limbah medis padat yang tidak menggunakan APD lengkap, masih terdapat kantong plastik untuk limbah medis yang tidak sesuai dengan kategori warna kantong plastik limbah medis, serta hasil pembakaran pada incenerator yang langsung dibuang ke TPA.

Tujuan dari penelitian ini untuk mengetahui pengelolaan limbah medis padat di RSUD Dr. R. Sosodoro Djatikoesoemo Bojonegoro. 


\section{METODE PENELITIAN}

Menggunakan metode penelitian deskriptif dengan tujuan utama untuk membuat gambaran atau deskripsi tentang suatu keadaan secara objektif (Notoatmodjo. S, 2005: 138), yaitu pengelolaan limbah medis padat rumah sakit. Data diperoleh dari data primer yang berasal dari pengamatan secara langsung di lapangan dan data sekunder yang diperoleh dari rumah sakit. Teknik pengumpulan data melalui observasi, wawancara dan pengukuran. Metode analisis data yaitu data disajikan dalam bentuk tabulasi dan dianalisis secara deskriptif.

\section{HASIL PENELITIAN DAN PEMBAHASAN}

Tabel 1

Hasil Penilaian Pengelolaan Limbah Medis Padat di RSUD DR. R. Sosodoro Djatikoesoemo Bojonegoro

\begin{tabular}{|c|l|c|c|c|c|c|}
\hline No. & \multicolumn{1}{|c|}{ Variabel } & Eobot & Nilai Max & Nilai Obs. & $\%$ & kriteria \\
\hline 1. & Tahap Penimbulan & 1 & 100 & 0 & 0 & TMS \\
\hline 2. & Tahap Penyimpanan & 2 & 200 & 152 & 76 & TMS \\
\hline 3. & Tahap Pengumpulan & 2 & 200 & 200 & 100 & MS \\
\hline 4. & Tahap Pengangkutan & 2 & 200 & 192 & 96 & MS \\
\hline 5. & $\begin{array}{l}\text { Tahap pemusnahan / } \\
\text { Penanganan Akhir }\end{array}$ & 3 & 300 & 195 & 65 & TMS \\
\hline
\end{tabular}

Pada tahap penimbulan limbah medis padat tidak dilakukan reduksi atau pengurangan limbah bahan yang tidak sekali pakai serta tidak adanya pengawasan terhadap setiap penggunaan bahan kimia yang berbahaya dan beracun. Seharusnya setiap rumah sakit harus melakukan reduksi limbah dimulai dari sumber serta harus mengelola dan mengawasi penggunaan bahan kimia yang berbahaya dan beracun.

Pada tahap penyimpanan sementara untuk limbah medis tidak dibedakan menurut tiap jenisnya dari sumber penghasil. Konstruksi tempat penyimpanan sementara limbah medis padat yang tersedia tidak sesuai dengan persyaratan yang telah ditetapkan mengacu pada Kepmenkes 1204 Tahun 2004. Pada rumah sakit masih terdapat tempat sampah yang tidak kedap air, bocor, tidak terdapat tutup. Seharusnya pemilahan limbah harus dilakukan dari sumber yang menghasilkan limbah, perwadahan limbah medis padat harus memenuhi persyaratan dengan penggunaan wadah / kantong plastik dan label yang sesuai pada tempat sampah.

Pada tahap pengumpulan limbah medis padat dibawa menggunakan troli khusus dari berbagai sumber penghasil. Kondisi TPS bersih dan memiliki kunci, tersedia kontainer dengan kapasitas yang memadai, tersedia fasilitas pencucian tangan, tidak ada tanda kehidupan vektor, dilengkapi dengan kunci, lokasi TPS strategis berjarak > 50 meter dari lokasi fasilitas umum, mudah dijangkau, jauh dari unit pelayanan dan dapur serta tidak rawan banjir. $\mathrm{Hal}$ ini sesuai dengan Kepmenkes No. 1204 Tahun 2004.
Pada tahap pengangkutan pengangkutan limbah keluar rumah sakit menggunakan kendaraan khusus, selama proses pengangkutan tidak ada limbah yang tercecer di lingkungan rumah sakit, troli yang digunakan terbuat dari bahan yang kuat, permukaan bagian dalam rata, kedap air, mudah diisi dan dikosongkan kembali, tidak menjadi sarang vektor serta tertutup. Hal ini sesuai dengan Kepmeknkes No. 1204 Tahun 2004. Petugas dalam melakukan tugasnya menggunakan APD namun tidak lengkap, petugas menggunakan topi / helm, masker, pakaian panjang, sepatu boot, sarung tangan khusus tetapi tidak menggunakan pelindung mata. Disarankan petugas yang menangani limbah medis padat harus menggunakan alat pelindung diri yang terdiri dari topi / helm, masker, pelindung mata, pakaian panjang, pelindung kaki / sepatu boot dan sarung tangan khusus (Kepmenkes No. 1204 Tahun 2004).

Pada tahap pemusnahan / penanganan akhir tidak dilakukan sterilisasi limbah medis padat yang akan digunakan kembali dan tidak ada penanganan khusus terhadap hasil pembakaran sehingga abu hasil pembakaran langsung dimasukkan kedalam sak dan langsung dibuang ke TPA. Seharusnya limbah medis padat yang akan digunakan kembali harus melalui proses sterilisasi sedangkan hasil pembakaran limbah medis padat tidak diperbolehkan dibuang langsung ke tempat pembuangan akhir limbah domestik sebelum aman bagi kesehatan sehingga harus dilakukan penanganan khusus. 


\section{Faktor Yang Mempengaruhi Jumlah Limbah Medis padat}

\section{Jumlah Pengunjung Yang Berobat}

Tabel 2

Jumlah Pengunjung yang Berobat

di RSUD DR. R. Sosodoro Djatikoesoemo Bojonegoro

\begin{tabular}{|c|c|c|c|c|c|c|c|c|c|}
\hline \multirow[b]{2}{*}{ No } & \multirow[b]{2}{*}{ Ruangan } & \multicolumn{7}{|c|}{ Tanggal } & \multirow{2}{*}{ 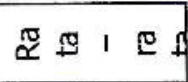 } \\
\hline & & 20 & 21 & 22 & 23 & 24 & 25 & 26 & \\
\hline 1. & Poli & 112 & 92 & 79 & 71 & 50 & 64 & - & 67 \\
\hline 2. & I.R.D & 53 & 49 & 35 & 28 & 24 & 24 & 29 & 35 \\
\hline 3. & Laboratorium & 78 & 61 & 54 & 45 & 59 & 46 & - & 49 \\
\hline 4. & Radiologi & 67 & 55 & 46 & 38 & 29 & 33 & - & 38 \\
\hline 5. & Hemodialisa & 17 & 11 & 9 & 7 & 8 & 8 & - & 8 \\
\hline
\end{tabular}

Dari tabel 2 dapat diketahui jumlah pengunjung yang berobat tiap hari rata - rata adalah 197 pasien. Pengunjung rumah sakit adalah orang yang datang ke rumah sakit dengan kepentingan untuk berobat. Semakin banyak pengunjung yang berobat, maka semakin banyak pula limbah medis padat yang dihasilkan oleh rumah sakit.

\section{Jumlah Penderita Yang di Rawat}

Tabel 3

Jumlah Penderita yang di Rawat Inap di RSUD DR. R. Sosodoro Djatikoesoemo Bojonegoro

\begin{tabular}{|c|c|c|c|c|c|c|c|c|c|}
\hline \multirow[b]{2}{*}{ No } & \multirow{2}{*}{ Ruangan } & \multicolumn{7}{|c|}{ Jumlah Pasien / Hari } & \multirow{2}{*}{$\begin{array}{c}\text { Rata - } \\
\text { rata }\end{array}$} \\
\hline & & 1 & 2 & 3 & 4 & 5 & 6 & 7 & \\
\hline 1 & Asoka & 39 & 39 & 40 & 40 & 39 & 38 & 38 & 39 \\
\hline 2 & Anyelir & 57 & 57 & 57 & 56 & 55 & 55 & 56 & 56 \\
\hline 3 & Nusa Indah & 18 & 17 & 17 & 14 & 14 & 14 & 16 & 16 \\
\hline 4 & Flamboyan & 33 & 33 & 33 & 35 & 35 & 34 & 36 & 34 \\
\hline 5 & Sakura & 20 & 18 & 18 & 16 & 16 & 19 & 15 & 17 \\
\hline 6 & Tulip & 26 & 27 & 27 & 26 & 27 & 27 & 27 & 27 \\
\hline 7 & Matahari & 25 & 25 & 25 & 24 & 25 & 25 & 24 & 25 \\
\hline 8 & ICU & 5 & 5 & 5 & 5 & 4 & 5 & 5 & 5 \\
\hline 9 & Melati & 16 & 17 & 17 & 17 & 17 & 17 & 17 & 17 \\
\hline 10 & Mawar & 11 & 11 & 10 & 10 & 11 & 9 & 9 & 10 \\
\hline 11 & Bugenvile & 10 & 10 & 9 & 11 & 11 & 11 & 9 & 10 \\
\hline 12 & WK & 9 & 9 & 9 & 9 & 9 & 9 & 8 & 9 \\
\hline 13 & $\mathrm{HCU}$ & 5 & 5 & 5 & 6 & 6 & 4 & 4 & 5 \\
\hline & JUMLAH & 274 & 274 & 272 & 269 & 269 & 267 & 264 & 270 \\
\hline
\end{tabular}

Dari tabel 3 dapat bahwa diketahui jumlah pasien yang dirawat di ruang perawatan rata - rata per harinya adalah 270 pasien. Semakin banyak penderita yang dirawat di rumah sakit, maka semakin banyak pula limbah medis padat yang dihasilkan oleh rumah sakit. Karena banyaknya jumlah penderita yang dirawat mempengaruhi jumlah limbah medis padat yang dihasilkan.

\section{Jenis Layanan Rumah Sakit}

RSUD Dr. R. Sosodoro Djatikoesoemo Bojonegoro memiliki 16 fasilitas pelayanan kesehatan, tetapi hanya 8 fasilitas pelayanan yang menghasilkan limbah medis padat meliputi pelayanan rawat darurat, rawat jalan (poliklinik), rawat inap, pelayanan sentral bedah, pelayanan intensif, pelayanan unggulan, laboratorium, farmasi. Banyaknya limbah medis padat yang dihasilkan oleh rumah sakit dipengaruhi oleh banyaknya jumlah jenis layanan yang ada di rumah sakit. Semakin banyak dan semakin lengkap jenis layanan yang ada di rumah sakit maka semakin banyak pula jumlah limbah medis padat yang dihasilkan.

Faktor - Faktor Penunjang Dalam Pengelolaan Limbah Medis Padat

\section{Pengorganisasian}

Untuk menjalankan tugas yang berhubungan dengan limbah medis padat, rumah sakit telah memiliki struktur organisasi. Sesuai dengan struktur tersebut pengelolaan limbah medis padat 
di dilakukan oleh bagian IPSRS (Instalasi Pemeliharaan Sarana Rumah Sakit). Pengorganisasian bertujuan membantu dalam proses pengelolaan limbah medis padat, hal tersebut merupakan faktor penunjang yang mempunyai keterkaitan dengan faktor - faktor yang lain. Oleh karena itu diperlukan dalam pengelolaan limbah medis padat.

\section{Ketenagaan}

Tenaga pengelolaan limbah medis padat terdiri dari 4 orang. 1 orang penanggung jawab, 1 orang petugas khusus pengelola limbah medis padat dan 2 orang cleaning service yang telah diberi pelatihan khusus secara internal oleh penanggung jawab pengelolaan limbah medis padat. Jumlah tenaga pengelolaan limbah medis tersebut masih kurang, karena limbah medis padat yang dihasilkan cukup banyak sehingga petugas yang ada cukup kualahan dalam menangani limbah medis padat.

\section{Perlengkapan dan Pendataan}

Dari hasil penelitian bahan dan perlengkapan yang digunakan untuk pengelolaan limbah medis padat cukup memenuhi syarat, namun pihak rumah sakit masih belum menggunakan kantong plastik yang sesuai dengan kode pedoman untuk limbah medis padat berdasarkan KepMenKes $1204 /$ Menkes/SK/X/2004. Selalu ada pencatatan dan laporan bulanan secara tertulis. Dengan tersedianya berbagai perlengkapan, maka proses pengelolaan akan menciptakan kualitas yang sesuai dengan persyaratan kesehatan lingkungan rumah sakit (Sahuri dan Iis, 2014). Demikian pula pendataan, dengan lengkapnya pendataan yang ada dii rumah sakit maka akan memperlancar pengelolaan limbah medis padat yang ada d rumah sakit.

\section{Biaya dan Anggaran}

Rumah sakit setiap tahunnya memiliki anggaran khusus untuk pengelolaan limbah padat, baik medis maupun non medis kurang lebih sebanyak 922.000 .000 per tahun. Jumlah anggaran tersebut telah memenuhi kebutuhan yang berkaitan dengan pengelolaan limbah padat medis maupun non medis. Ketersediaan biaya yang mencukupi sangat menunjang pelaksanaan kegiatan pengelolaan limbah medis padat di rumah sakit (Sahuri dan Iis, 2014).

\section{Peraturan dan Landasan Kerja}

Peraturan dan landasan kerja yang digunakan dalam pengelolaan sampah medis padat adalah KepMenKes 1204/Menkes/SK/X/2004 tentang Persyaratan Kesehatan Lingkungan Rumah Sakit dan PP No. 85 Tahun 1999 tentang Pengelolaan Limbah B3.

\section{Kesimpulan :}

Tahap penimbulan, tempat penyimpanan sementara dan pemusnahan akhir limbah medis padat tidak memenuhi syarat. Tahap pengumpulan dan pelaksanaan pengangkutan limbah medis padat memenuhi syarat. Faktor faktor yang mempengaruhi jumlah limbah medis padat meliputi jumlah pengunjung yang berobat, jumlah penderita yang dirawat inap, Jenis fasilitas layanan. Faktor - faktor penunjang dalam pengelolaan limbah medis padat meliputi jumlah tenaga pengelolaan limbah medis padat, perlengkapan yang digunakan, biaya dan anggaran secara khusus. Peraturan dan landasan kerja yang digunakan.

\section{Saran :}

1. Pada penimbulan limbah medis padat sebaiknya rumah sakit melakukan reduksi limbah mulai dari sumber penghasil limbah medis padat serta melakukan pengawasan terhadap penggunaan bahan kimia yang berbahaya dan beracun.

2. Pada tempat penyimpanan sementara limbah medis padat sebaiknya terdapat pemisahan limbah medis padat menurut jenisnya, tempat sampah dan warna kantong plastik yang digunakan disesuaikan dengan pedoman.

3. Pada pengangkutan limbah medis padat sebaiknya petugas pengangkut menggunakan APD yang lengkap.

4. Pada pemusnahan / penanganan akhir limbah medis padat seharusnya rumah sakit melakukan pemanfaatan kembali limbah medis padat melalui proses sterilisasi dan melakukan penanganan khusus terhadap abu hasil pembakaran limbah medis padat.

\section{DAFTAR PUSTAKA}

Anonymous. 2014. Pedoman Penulisan Karya Tulis Ilmiah. Surabaya, Kesehatan Lingkungan Surabaya.

Asmadi, 2013. Pengelolaan Limbah Medis Rumah Sakit. Yogyakarta, Gosyen publishing: 1-57.

Budiman, Chandra, 2012. Pengantar IImu Kesehatan Lingkungan. Jakarta, Buku Kedokteran EGC: 111 - 123.

Depkes RI, 2002. Pedoman Sanitasi Rumah Sakit di Indonesia. Jakarta, Direktorat Jendral PPM \& PLP: 49-86.

Febrina, Rahma, 2011. Sistem Pengelolaan Sampah Padat di Rumah Sakit $X$ Jakarta Tahun 2011. http://lontar.ui.ac.id/file?file=digital/ 20294084-S-Rahma\%20Febrina.pdf. 6 Januari 2014.

Keputusan Menteri Kesehatan Republik Indonesia Nomor 1204/ Menkes/ SK/ X/ 2004 Tentang Persyaratan Kesehatan Lingkungan Rumah Sakit.

Latief, A.S. 2010. Manfaat dan Dampak Penggunaan Insinerator Terhadap Lingkungan.http://www.polines.ac.id/te knis/upload/jurnal/jurnal teknis 13364 71916.pdf. 10 Januari 2014.

Notoatmodjo, Soekidjo, 2003. IImu Kesehatan Masyarakat (Prinsip - Prinsip Dasar). Jakarta, PT. Asdi Mahasatya: 166-169. 
Notoatmodjo, Soekidjo, 2005. Metodologi Penelitian Kesehatan. Jakarta, PT. Asdi Mahasatya: 166-169.

Peraturan Menteri Kesehatan Republik Indonesia Nomor 340/ Menkes/ Per/ III/ 2010 Tentang Klasifikasi Rumah Sakit.

Peraturan Pemerintah Republik Indonesia Nomor 18 Tahun 1999 Tentang Pengelolaan Limbah Bahan Berbahaya dan Beracun.

Pratiwi, Dyah, 2013. Analisis Pengeolaan Limbah Medis Padat Pada Puskesmas Kabupaten Pati. http://lib.unnes.ac.id/18384/1/64504 08020.pdf. 10 Januari 2014.

Sarudji, Didik, 1985. Pengelolaan Sampah. Surabaya, APK Surabaya: $28-31$.

Sarudji, Didik, 2010. Kesehatan Lingkungan. Bandung, CV. Karya Putra Darwati : $310-340$.

S., Iis, and S., Chalid, 2014. Manajemen Limbah Medis Rumah di Sakit Umum Daerah Arifin Achmad Provinsi Riau. http://jom.unri.ac.id/ index.php/JOMFSIP/article/viewFile/288 2/2796. 11 Agustus 2014.
Undang-undang Republik Indonesia Nomor 18 Tahun 2008 Tentang Pengelolaan Sampah.

Undang-Undang Republik Indonesia Nomor 44 Tahun 2009 Tentang Rumah Sakit.

Waldi, Reza, 2011. Ruang Lingkup Kesehatan Lingkungan. http://rezawaldi.blogspot.com/. 10 Januari 2014.

WHO, 2005. Pengelolaan Aman Limbah Layanan Kesehatan. Jakarta, Buku Kedokteran EGC.

Wulandari, Puri, 2011. Upaya Minimasi dan Pengelolaan Limbah Medis di Rumah Sakit Haji Jakarta Tahun 2011. http://lontar.ui.ac.id/ file?file $=$ digital/20293959-SPuri\%20Wulandari.pdf. 17 Juli 2014.

Yasin, S.R., 2013. Gambaran Sistem Pengelolaan Sampah Medis dan Non Medis di RSUD. Prof. Dr. H. Aloe Saboe. http://www.sryasin. Word press.com/. 10 Desember 2013. 